REVIEW SUMMARY

CLIMATE CHANGE

\section{Biodiversity redistribution under climate change: Impacts on ecosystems and human well-being}

Gretta T. Pecl, ${ }^{*}$ Miguel B. Araújo, $†$ Johann D. Bell, Julia Blanchard, Timothy C. Bonebrake, I-Ching Chen, Timothy D. Clark, Robert K. Colwell, Finn Danielsen, Birgitta Evengård, Lorena Falconi, Simon Ferrier, Stewart Frusher, Raquel A. Garcia, Roger B. Griffis, Alistair J. Hobday, Charlene Janion-Scheepers, Marta A. Jarzyna, Sarah Jennings, Jonathan Lenoir, Hlif I. Linnetved, Victoria Y. Martin, Phillipa C. McCormack, Jan McDonald, Nicola J. Mitchell, Tero Mustonen, John M. Pandolfi, Nathalie Pettorelli, Ekaterina Popova, Sharon A. Robinson, Brett R. Scheffers, Justine D. Shaw, Cascade J. B. Sorte, Jan M. Strugnell, Jennifer M. Sunday, Mao-Ning Tuanmu, Adriana Vergés, Cecilia Villanueva, Thomas Wernberg, Erik Wapstra, Stephen E. Williams

BACKGROUND: The success of human societies depends intimately on the living components of natural and managed systems. Although the geographical range limits of species are dynamic and fluctuate over time, climate change is impelling a universal redistribution of life on Earth. For marine, freshwater, and terrestrial species alike, the first response to changing climate is often a shift in location, to stay within preferred environmental conditions. At the cooler extremes of their distributions, species

are moving poleward, whereas range limits are contracting at the warmer range edge, where temperatures are no longer tolerable. On land, species are also moving to cooler, higher elevations; in the ocean, they are moving to colder water at greater depths. Because different species respond at different rates and to varying degrees, key interactions among species are often disrupted, and new interactions develop. These idiosyncrasies can result in novel biotic communities and rapid changes in ecosystem functioning,

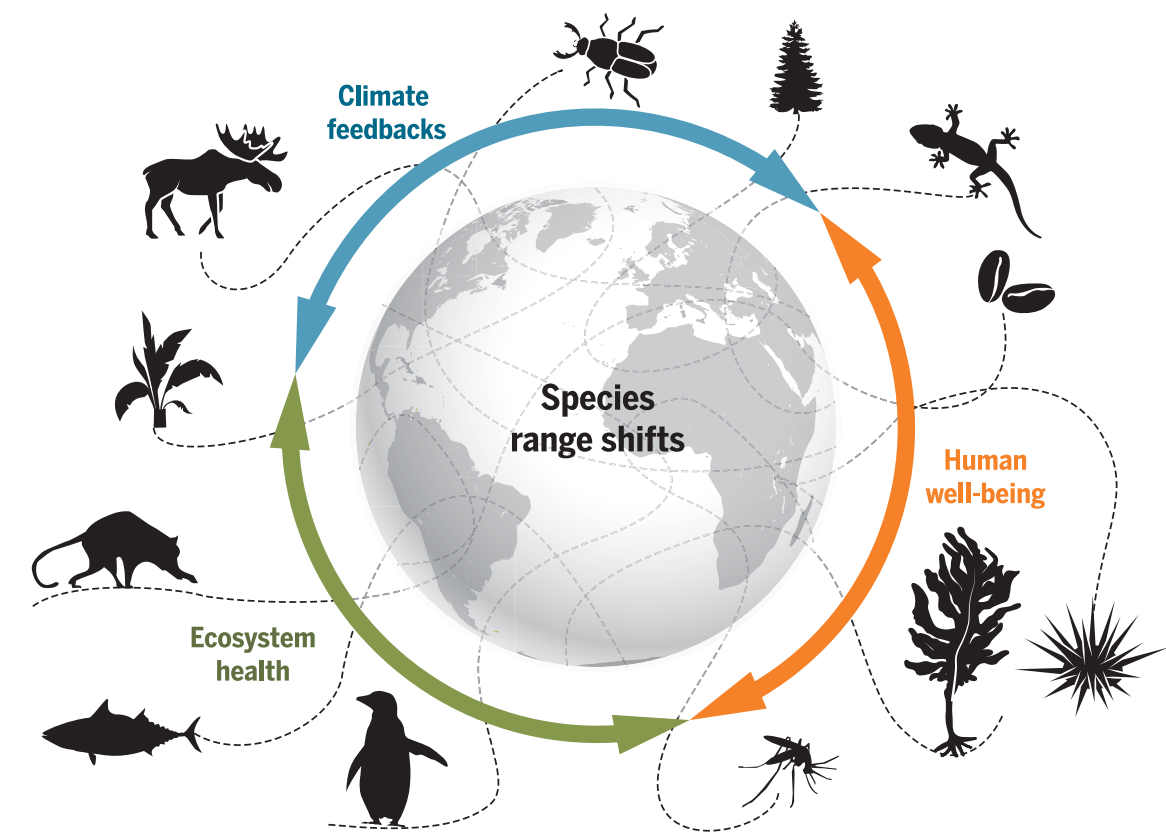

As the global climate changes, human well-being, ecosystem function, and even climate itself are increasingly affected by the shifting geography of life. Climate-driven changes in species distributions, or range shifts, affect human well-being both directly (for example, through emerging diseases and changes in food supply) and indirectly (by degrading ecosystem health). Some range shifts even create feedbacks (positive or negative) on the climate system, altering the pace of climate change.

with pervasive and sometimes unexpected consequences that propagate through and affect both biological and human communities.

ADVANCES: At a time when the world is anticipating unprecedented increases in human population growth and demands, the ability of natural ecosystems to deliver ecosystem services is being challenged by the largest climate-driven global redistribution of species since the Last Glacial Maximum. We demonstrate the serious consequences of this species redistribution for economic development, livelihoods, food security,

\section{ON OUR WEBSITE}

Read the full article at http://dx.doi. org/10.1126/ science.aai9214

ra radically reshaping the pattern of human wellbeing between regions and different sectors and potentially leading to substantial conflict. The pervasive impacts of changes in species distribution transcend single systems or dimensions, with feedbacks and linkages between multiple interacting scales and through whole ecosystems, inclusive of humans. We argue that the negative effects of climate change cannot be adequately anticipated or prepared for unless species responses are explicitly included in decision-making and global strategic frameworks.

OUTLOOK: Despite mounting evidence for the pervasive and substantial impacts of a climatedriven redistribution of Earth's species, current global goals, policies, and international agreements fail to account for these effects. With the predicted intensification of species movements and their diverse societal and environmental impacts, awareness of species "on the move" should be incorporated into local, regional, and global assessments as standard practice. This will raise hope that future targets-whether they be global sustainability goals, plans for regional biodiversity maintenance, or local fishing or forestry harvest strategies-can be achievable and that society is prepared for a world of universal ecological change. Human society has yet to appreciate the implications of unprecedented species redistribution for life on Earth, including for human lives. Even if greenhouse gas emissions stopped today, the responses required in human systems to adapt to the most serious effects of climatedriven species redistribution would be massive. Meeting these challenges requires governance that can anticipate and adapt to changing conditions, as well as minimize negative consequences.

The list of author affiliations is available in the full article online. *Corresponding author. Email: gretta.pec@@utas.edu.au $\dagger$ All authors after the first author are listed alphabetically. Cite this article as G. T. Pecl et al., Science 355, eaai9214 (2017). DOI: $10.1126 /$ science.aai9214 
REVIEW

CLIMATE CHANGE

\section{Biodiversity redistribution under climate change: Impacts on ecosystems and human well-being}

Gretta T. Pecl, ${ }^{1,2 *}$ Miguel B. Araújo, ${ }^{3,4,5} \dagger$ Johann D. Bell,,${ }^{6,7}$ Julia Blanchard,, 2 Timothy C. Bonebrake, ${ }^{8}$ I-Ching Chen, ${ }^{9}$ Timothy D. Clark, ${ }^{1,10}$ Robert K. Colwell,, ,11,12,13 Finn Danielsen, ${ }^{14}$ Birgitta Evengård, ${ }^{15}$ Lorena Falconi, ${ }^{16}$ Simon Ferrier, ${ }^{17}$ Stewart Frusher, ${ }^{1,2}$ Raquel A. Garcia, ${ }^{18,19}$ Roger B. Griffis, ${ }^{20}$ Alistair J. Hobday, ${ }^{2,21}$ Charlene Janion-Scheepers, ${ }^{22}$ Marta A. Jarzyna, ${ }^{23}$ Sarah Jennings, ${ }^{2,24}$ Jonathan Lenoir, ${ }^{25}$ Hlif I. Linnetved, ${ }^{26}$ Victoria Y. Martin, ${ }^{27}$ Phillipa C. McCormack, ${ }^{28}$ Jan McDonald, ${ }^{2,28}$ Nicola J. Mitchell, ${ }^{29}$ Tero Mustonen, ${ }^{30}$ John M. Pandolfi, ${ }^{31}$ Nathalie Pettorelli, ${ }^{32}$ Ekaterina Popova, ${ }^{33}$ Sharon A. Robinson, ${ }^{34}$ Brett R. Scheffers, ${ }^{35}$ Justine D. Shaw, ${ }^{36}$ Cascade J. B. Sorte, ${ }^{37}$ Jan M. Strugnell, ${ }^{38,39}$ Jennifer M. Sunday, ${ }^{40}$ Mao-Ning Tuanmu, ${ }^{41}$ Adriana Vergés, ${ }^{42}$ Cecilia Villanueva, ${ }^{1,2}$ Thomas Wernberg, ${ }^{29,43}$ Erik Wapstra, ${ }^{44}$ Stephen E. Williams ${ }^{16}$

Distributions of Earth's species are changing at accelerating rates, increasingly driven by humanmediated climate change. Such changes are already altering the composition of ecological communities, but beyond conservation of natural systems, how and why does this matter? We review evidence that climate-driven species redistribution at regional to global scales affects ecosystem functioning, human well-being, and the dynamics of climate change itself. Production of natural resources required for food security, patterns of disease transmission, and processes of carbon sequestration are all altered by changes in species distribution. Consideration of these effects of biodiversity redistribution is critical yet lacking in most mitigation and adaptation strategies, including the United Nation's Sustainable Development Goals.

T he history of life on Earth is closely associated with environmental change on multiple spatial and temporal scales (I). A critical component of this association is the capacity for species to shift their distributions in response to tectonic, oceanographic, or climatic events
(2). Observed and projected climatic changes for the 21st century, most notably global warming, are comparable in magnitude to the largest global changes in the past 65 million years $(3,4)$. The combined rate and magnitude of climate change is already resulting in a global-scale biological re- sponse. Marine, freshwater, and terrestrial organisms are altering distributions to stay within their preferred environmental conditions (5-8), and species are likely changing distributions more rapidly than they have in the past (9). Unlike the introduction of non-native species, which tends to be idiosyncratic and usually depends on humanmediated transport, climate-driven redistribution is ubiquitous, follows repeated patterns, and is poised to influence a greater proportion of Earth's biota. This redistribution of the planet's living organisms is a substantial challenge for human society.

Despite agreements to curb greenhouse gas emissions, the climate will continue to change for at least the next several hundred years, given the inertia of the oceanic and atmospheric circulation systems (10), and species will continue to respond, often with unpredictable consequences. Since 1880, there has been an average warming of $0.85^{\circ} \mathrm{C}$ globally (10), resulting in well-documented shifts in species distributions with far-reaching implications for human societies, yet governments have agreed to accept more than double this amount of warming in the future (e.g., the $2^{\circ} \mathrm{C}$ target from the Paris Conference of Parties 21). Moreover, current global commitments will only limit warming to $2.7^{\circ}$ to $3.7^{\circ} \mathrm{C}$, more than three to four times the warming already experienced (II). To date, all key international discussions and agreements regarding climate change have focused on the direct socioeconomic implications of emissions reduction and on funding mechanisms; shifting natural ecosystems have not yet been considered in detail.

Here we review the consequences of climatedriven species redistribution for economic development and the provision of ecosystem services, including livelihoods, food security, and culture, as well as for feedbacks on the climate itself (Fig. 1 and table $\mathrm{S} 1$ ). We start by examining the impacts of climate-driven species redistribution on ecosystem health, human well-being, and the climate system, before highlighting the governance challenges these impacts individually and collectively

${ }^{1}$ Institute for Marine and Antarctic Studies, Hobart, Tasmania 7001, Australia. ${ }^{2}$ Centre for Marine Socioecology, Hobart, Tasmania 7001, Australia. ${ }^{3}$ Department of Biogeography and Global Change, Museo Nacional de Ciencias Naturales, Consejo Superior de Investigaciones Científicas, 28006 Madrid, Spain. ${ }^{4}$ Centro de Investigação em Biodiversidade e Recursos Geneticos,

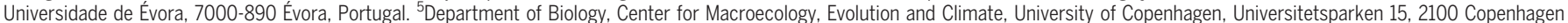
0, Denmark. ${ }^{6}$ Australian National Centre for Ocean Resources and Security, University of Wollongong, New South Wales 2522 , Australia. ${ }^{7}$ Betty and Gordon Moore Center for Science and

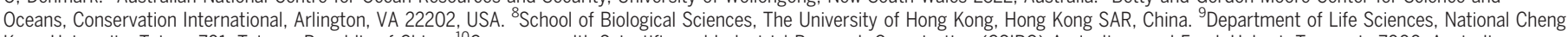
Kung University, Tainan 701, Taiwan, Republic of China. ${ }^{10}$ Commonwealth Scientific and Industrial Research Organization (CSIRO) Agriculture and Food, Hobart, Tasmania 7000, Australia. ${ }^{11}$ Department of Ecology and Evolutionary Biology, University of Connecticut, Storrs, CT 06269, USA. ${ }^{12}$ University of Colorado Museum of Natural History, Boulder, CO 80309, USA.

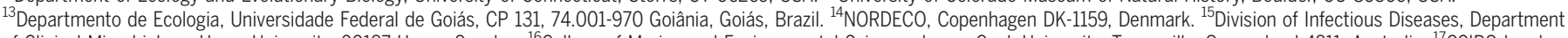

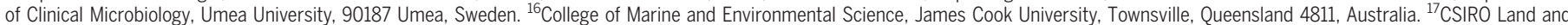

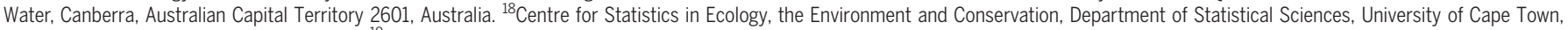
Rondebosch 7701, Cape Town, South Africa. ${ }^{19}$ Centre for Invasion Biology, Department of Botany and Zoology, Faculty of Science, Stellenbosch University, Matieland 7602, South Africa.

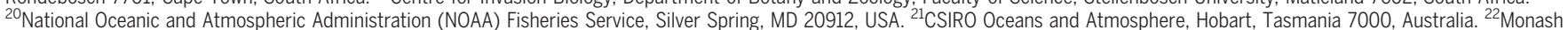

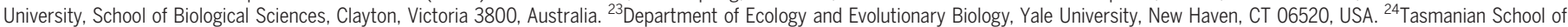
Business and Economics, University of Tasmania, Hobart, Tasmania 7001, Australia. ${ }^{25}$ EDYSAN (FRE 3498 CNRS-UPJV), Université de Picardie Jules Verne, 80037 Amiens Cedex 1, France. ${ }^{26}$ Institute of Food and Resource Economics, Faculty of Science, University of Copenhagen, Rolighedsvej 25, DK-1958 Frederiksberg C, Denmark. ${ }^{27}$ School of Environment, Science and

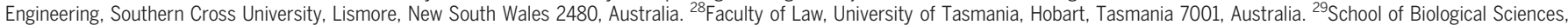

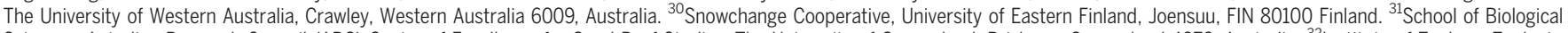

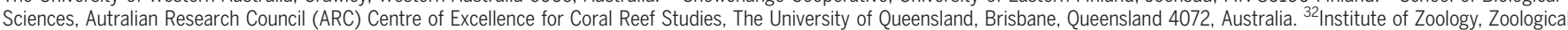

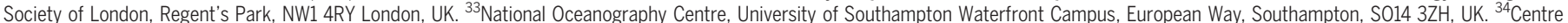

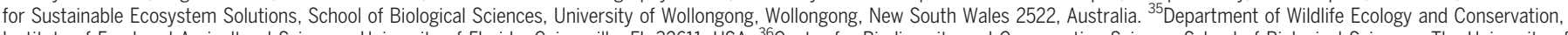

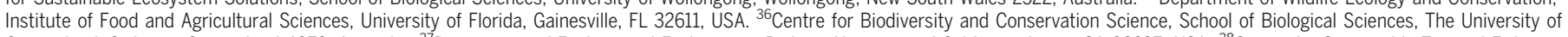

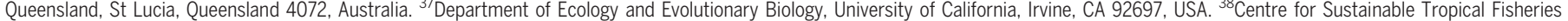
and Aquaculture, College of Science and Engineering, James Cook University, Townsville, 4811 Queensland, Australia. ${ }^{39}$ Department of Ecology, Environment and Evolution, School of Life

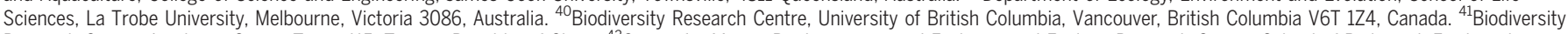
Research Center, Academia Sinica, Taipei 115, Taiwan, Republic of China. ${ }^{42}$ Centre for Marine Bio-Innovation and Evolution and Ecology Research Centre, School of Biological, Earth and Environmental Sciences, University of New South Wales, Sydney, New South Wales 2052, Australia. ${ }^{43}$ Oceans Institute, The University of Western Australia, Perth, Western Australia 6009, Australia. ${ }^{44}$ School of Biological Sciences, University of Tasmania, Hobart, Tasmania 7001, Australia.

*Corresponding author. Email: gretta.pecı@utas.edu.au †All authors after the first author are listed alphabetically. 
create. Critically, the pervasive effects of changes in species distribution transcend single systems or dimensions, with feedbacks and linkages among multiple interacting spatial and temporal scales and through entire ecosystems, inclusive of humans (Figs. 2 and 3). We conclude by considering species redistribution in the context of Earth systems and sustainable development. Our Review suggests that the negative effects of climate change cannot be adequately mitigated or minimized unless species responses are explicitly included in decision-making and strategic frameworks.

\section{Biological responses and ecosystem health}

Species are affected by climate in many ways, including range shifts, changes in relative abundance within species ranges, and subtler changes in activity timing and microhabitat use $(12,13)$. The geographic distribution of any species depends upon its environmental tolerance, dispersal constraints, and biological interactions with other species (14). As climate changes, species must either tolerate the change, move, adapt, or face extinction (15). Surviving species may thus have increased capacity to live in new locations or decreased ability to persist where they are currently situated (13).

Shifts in species distributions across latitude, elevation, and with depth in the ocean have been extensively documented (Fig. 1). Meta-analyses show that, on average, terrestrial taxa move poleward by $17 \mathrm{~km}$ per decade (5) and marine taxa by $72 \mathrm{~km}$ per decade $(6,16)$. Just as terrestrial species on mountainsides are moving upslope to escape warming lowlands (17), some fish species are driven deeper as the sea surface warms (18).

The distributional responses of some species lag behind climate change $(6,8)$. Such lags can arise from a range of factors, including species-specific physiological, behavioral, ecological, and evolutionary responses (12). Lack of adequate habitat connectivity and access to microhabitats and associated microclimates are expected to be critical in increasing exposure to macroclimatic warming and extreme heat events, thus delaying shifts of some species (19). Furthermore, distribution shifts are often heterogeneous across geographic gradients when factors other than temperature drive species redistribution. For example, precipitation changes or interspecific interactions can cause downward elevation shifts as climate warms (20). Although species may adapt to changing climates, either through phenotypic plasticity or natural selection (21), all species have limits to their capacity for adaptive response to changing environments (12), and these limits are unlikely to increase for species already experiencing warm temperatures close to their tolerance limits (22).

The idiosyncrasies of species responses to climate change can result in discordant range shifts, leading to novel biotic communities as species separate or come into contact in new ways (23). In turn, altered biotic interactions hinder or facilitate further range shifts, often with cascading effects (24). Changes in predation dynamics, herbivory, hostplant associations, competition, and mutualisms can all have substantial impacts at the community level $(16,25)$. A case in point involves the expected effects of crabs invading the continental shelf habitat of Antarctic seafloor echinoderms and mollusks-species that have evolved in the absence

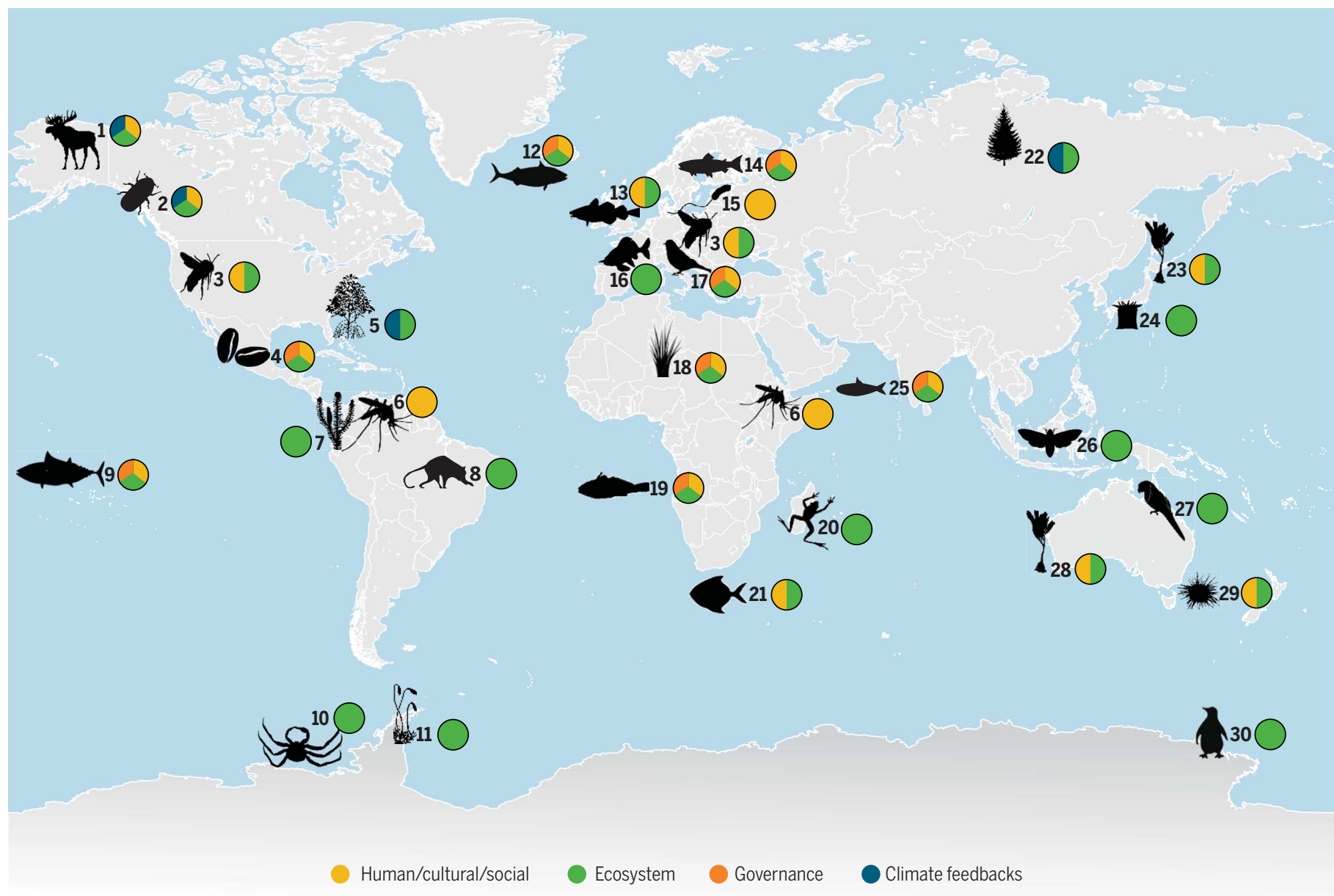

Fig. 1. Climate-driven changes in the distribution of life on Earth are affecting ecosystem health, human well-being, and the dynamics of climate change, challenging local and regional systems of governance. Examples of documented and predicted climate-driven changes in the distribution of species throughout marine, terrestrial, and freshwater systems of the globe in tropical, temperate, and polar regions are shown. Details of the impacts associated with each of these changes in distribution are provided in table S1, according to the numbered key, and the links to specific Sustainable Development Goals are given in table S2. 
of skeleton-crushing predators (26). The community impacts of shifting species can be of the same or greater magnitude as the introduction of nonnative species (16), itself recognized as one of the primary drivers of biodiversity loss (27).

When species range shifts occur in foundation or habitat-forming species, they can have pervasive effects that propagate through entire communities (28). In some cases, the impacts are so severe that species redistribution alters ecosystem productivity and carbon storage. For example, climatedriven range expansion of mangroves worldwide, at the expense of saltmarsh habitat, is changing local rates of carbon sequestration (29). The loss of kelp-forest ecosystems in Australia and their replacement by seaweed turfs have been linked to increases in herbivory by the influx of tropical fishes, exacerbated by increases in water temperature beyond the kelp's physiological tolerance limits $(30,31)$. Diverse disruptions from the redistribution of species include effects on terrestrial productivity (32), impacts on marine community assembly (33), and threats to the health of freshwater systems from widespread cyanobacteria blooms (34).

The effects on ecosystem functioning and condition arising from species turnover and changes in the diversity of species within entire communities are less well understood. The redistribution of species may alter the community composition in space and time (beta diversity), the number of species co-occurring at any given location (alpha diversity), and/or the number of species found within a larger region (gamma diversity) (35). The diversity and composition of functional traits within communities may also change as a result of species range shifts (36), although changes in functional traits may occur through alterations in relative abundance or community composition, without changes in species richness. Increasingly, evidence indicates that species diversity, which underlies functional diversity, has a positive effect on the mean level and stability of ecosystem functioning at local and regional scales (37). It therefore appears likely that any changes in diversity resulting from the redistribution of species will have indirect consequences for ecosystem condition.

Extinction risk from climate change has been widely discussed and contested (38-40), and predictions of extinction risk for the 21st century are considerable (41). In some cases, upslope migration allows mountain-dwelling species to track suitable climate, but topography and range loss can sometimes trap species in isolated and eventually unsuitable habitats (42). The American pika (Ochotona princeps) has been extirpated or severely diminished in some localities, signaling climateinduced extinction or at least local extirpation (43). Complicated synergistic drivers or "extinction debt"a process in which functional extinction precedes physical extinction-may make climate-induced extinction seem a distant threat. However, the disappearance of the Bramble Cay melomys (Melomys rubicola), an Australian rodent declared extinct due to sea level rise (44), shows that anthropogenic climate change has already caused irreversible species loss.
Notwithstanding the rich body of evidence from the response to climate change of species and ecosystems in the fossil record (45), understanding more recent, persistent responses to climate change usually requires several decades of data to rigorously assess pre- and postclimate change trends at the level of species and ecosystems (46). Such long-term data sets for biological systems are rare, and recent trends of declining funding undermine the viability of monitoring programs required to document and respond to climate change.

\section{Human well-being}

The well-being of human societies is tied to the capacity of natural and altered ecosystems to produce a wide range of goods and services. Human well-being, survival, and geographical distribution have always depended on the ability to respond to environmental change. The emergence of early humans was likely conditioned by a capacity to switch prey and diets as changing climatic conditions made new resources available (47). However, recent technological changes in agriculture, forestry, and fisheries have weakened the direct link between human migration and survival. Now, human societies rely more on technological and behavioral innovation to accommodate human demography, trade and economics, and food production to changing species distribution patterns. The redistributions of species are expected to affect the availability and distribution of goods and services for human well-being in a number of ways, and the relative immobility of many human societies, largely imposed by jurisdictional borders, has limited capacity to respond to environmental change by migration.

Redistributions of species are likely to drive major changes in the supply of food and other products. For example, the relative abundance of skipjack tuna in the tropical Pacific, which underpins government revenue and food security for many small island states, is expected to become progressively greater in eastern areas of the western and central Pacific Ocean, helping to offset the projected ubiquitous decline in the supply of fish from degraded coral reefs in that region (48). Conversely, it is estimated that an average of $34 \%$ of European forest lands, currently covered with valuable timber trees, such as Norway spruce, will be suitable only for Mediterranean oak forest vegetation by 2100 , resulting in much lower economic returns for forest owners and the timber industry (49).

The indirect effects of climate change on food webs are also expected to compound the direct effects on crops. For example, the distribution and abundance of vertebrate species that control crop pests are predicted to decline in European states, where agriculture makes important contributions to the gross domestic product (50). Shifts in the spatial distribution of agriculture will be required to counter the impact of these combined direct and indirect effects of changing climate. Geographic shifts in natural resource endowments and in systems supporting agriculture, forestry, fisheries, and aquaculture will result in winners and losers, with many of the negative effects likely to occur in developing countries (51). A prime example is the projected effect of climate change on the supply of coffee, with principal coffee-growing regions expected to shift (52).

Species range shifts are also affecting the intrinsic and economic values of recreation and tourism, in both negative and positive ways (53). The buildup of jellyfish due to warmer temperatures in a Mediterranean lagoon has had a negative effect on local economies linked to recreation, tourism, and fishing (54). In southeast Australia, a rangeextending sea urchin has overgrazed macroalgae, resulting in localized loss of up to 150 associated taxa and contributing to reduced catch limits for popular recreational fisheries species dependent on large seaweed (55). Impacts have been positive in some contexts, such as the recent emergence of highly prized species in recreational fishing areas (53).

Indirect effects from changes in species distributions that underpin society and culture can be dramatic. In the Arctic, changes in distributions of fish, wild reindeer, and caribou are affecting the food security, traditional knowledge systems, and endemic cosmologies of indigenous societies (Figs. 1 and 2) (7). In partial response, the Skolt Sámi in Finland have introduced adaptation measures to aid survival of Atlantic salmon stocks faced with warming waters and to maintain their spiritual relationship with the species. These measures include increasing the catch of pike to reduce predation pressure on salmon. In the East Siberian tundra, faced with melting permafrost, the Chukchi people are struggling to maintain their traditional nomadic reindeer-herding practices (56) (Fig. 2). Citizen-recording of climate-induced changes to complement assessments based on scientific sampling and remote sensing forms part of their strategy to maintain traditional practices.

Human health is also likely to be seriously affected by changes in the distribution and virulence of animal-borne pathogens, which already account for $70 \%$ of emerging infections $(57,58)$. Movement of mosquitoes in response to global warming is a threat to health in many countries through predicted increases in the number of known and potentially new diseases (Fig. 3). Malaria, the most prevalent mosquito-borne disease, has long been a risk for almost half of the world's population, with more than 200 million cases recorded in 2014 (59). Malaria is expected to reach new areas with the poleward and elevational migration of Anopheles mosquito vectors (60). Climate-related transmission of malaria can result in epidemics due to lack of immunity among local residents (59) and will challenge health systems at national and international scales, diverting public- and privatesector resources from other uses.

The winners and losers arising from the redistributions of species will reshape patterns of human well-being among regions and sectors of industry and communities (61). Those regions with the strongest climate drivers, with the mostsensitive species, and where humans have the least capacity to respond will be among the most affected. Developing nations, particularly those near the equator, are likely to experience greater climaterelated local extinctions due to poleward and 
elevational range shifts (62) and will face greater economic constraints. In some cases, species redistribution will also lead to substantial conflictthe recent expansion of mackerel into Icelandic waters is a case in point (Fig. 1 and table S1). The mackerel fishery in Iceland increased from 1700 metric tons in 2006 to 120,000 metric tons in 2010 , resulting in "mackerel wars" between Iceland and competing countries that have traditionally been allocated mackerel quotas (63). Likewise, with upslope shift of climate zones in the Italian Alps, intensified conflict is anticipated between recreation and biodiversity sectors. For example, climate-driven contractions in the most valuable habitat for high-elevation threatened bird species and for ski trails are predicted to increase, along with an increase in the degree of overlap between the bird habitat and the areas most suitable for future ski trail construction (64).

\section{Climate feedbacks}

Species redistributions are expected to influence climate feedbacks via changes in albedo, biologically driven sequestration of carbon from the atmosphere to the deep sea (the "biological pump"), and the release of greenhouse gases (65). For instance, terrestrial plants affect albedo via leaf area and color and regulate the global carbon cycle through $\mathrm{CO}_{2}$ atmosphere-land exchanges. Similarly, $\mathrm{CO}_{2}$ atmosphere-ocean exchanges are biologically modulated by $\mathrm{CO}_{2}$-fixing photosynthetic phytoplankton and by the biological pump that exports carbon into deep ocean reservoirs (66).

The climate-driven shifts in species distributions most likely to affect biosphere feedbacks involve redistribution of vegetation on land (Figs. 2 and 4) and phytoplankton in the ocean. Decreased albedo, arising from the combined effect of earlier snowmelt and increasing shrub density at high latitudes, already contributes to increased net radiation and atmospheric heating, amplifying highlatitude warming (67). Thus, continued warming will decrease the albedo in the Arctic, not only through a decline in snow cover but also through a northward shift of coniferous trees (Fig. 2). Pearson et al. (68) projected that by 2050 , vegetation in the Arctic will mostly shift from tundra (dominated by lichens and mosses with high albedo) to boreal forest (dominated by coniferous trees with low albedo). Additionally, the greenhouse effect may be amplified by top-of-atmosphere radiative

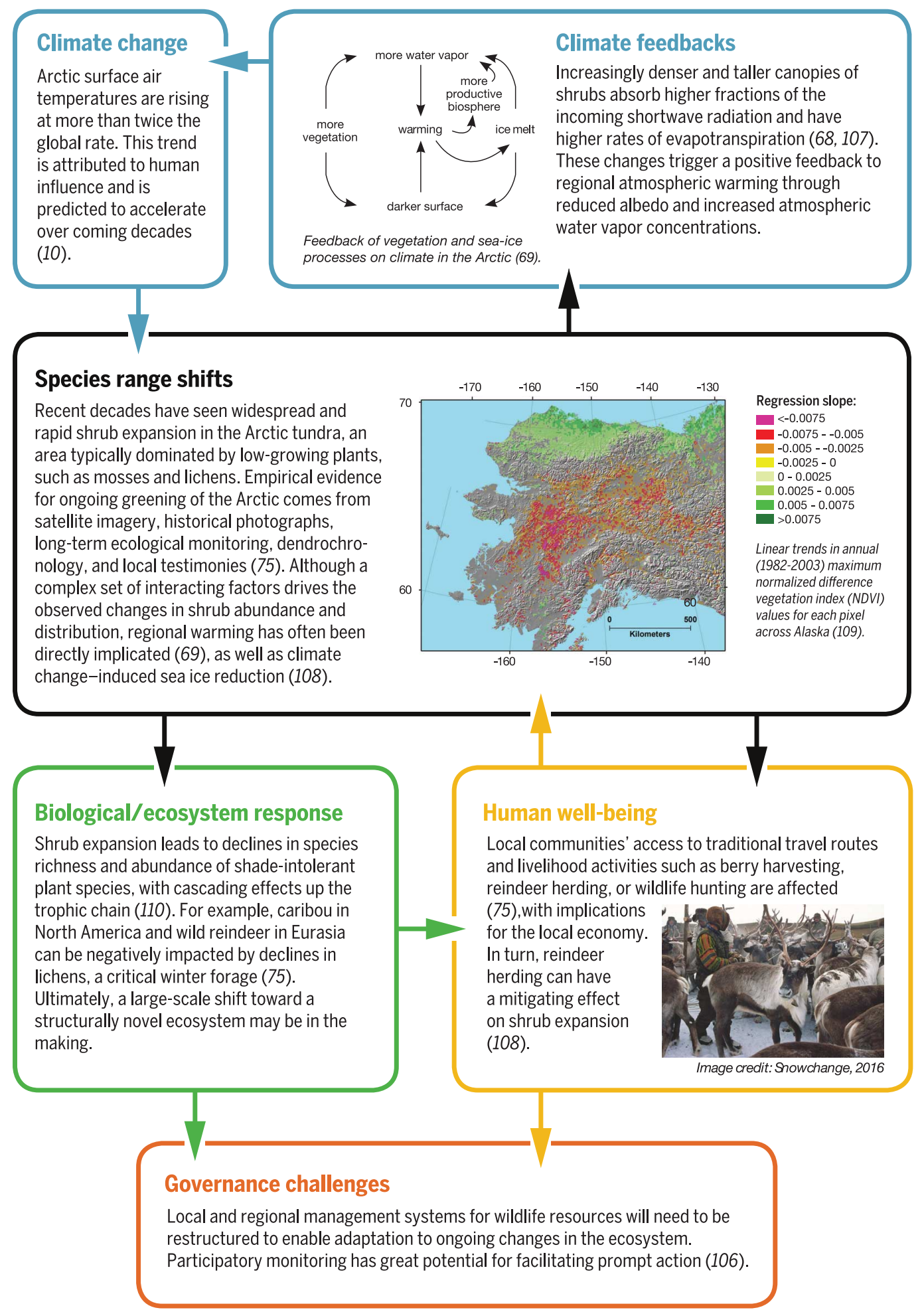

Fig. 2. Species on the move drive greening of the Arctic. Changes in species distribution can lead to climate feedbacks, changes in ecosystem services, and impacts on human societies, with feedbacks and linkages between each of these dimensions, illustrated here through climate-driven changes in Arctic vegetation. See Fig. 4 for a more comprehensive description of the direct and indirect climate feedbacks. See also $(10,68,69,75,106-110)$. 
imbalance from enhanced evapotranspiration associated with the greening of the Arctic (69). At low latitudes, ongoing plant redistribution [e. g., mangrove expansion and forest dieback (29)] potentially amplifies climate warming through carbon-cycle feedbacks (70). However, future projections in the tropics are uncertain because of a lack of close climatic analogs from which to extrapolate (71).

Species redistribution at high latitudes also affects vegetation state indirectly through pests like defoliators and bark beetles that are moving northward and upslope in boreal forests (72) (Figs. 1, 2, and 4). The combined effects of increasing temperatures and droughts increase plant stress, thus contributing to the severity of pest outbreaks and tree dieback. These processes, in turn, increase fuel loads and fire frequency (73), ultimately driving additional feedback through massive biomass burning and $\mathrm{CO}_{2}$ release. Finally, increased shrub canopy cover at high latitudes may locally reduce soil temperatures through a buffering effect (74), slowing the release of $\mathrm{CO}_{2}$ from permafrost degradation, thus potentially mitigating warming (75) (Fig. 2).

Redistribution of marine phytoplankton is expected to affect the ocean's biological and carbonate pumps and the production of atmospheric aerosols. The subpolar North Atlantic, which is already highly productive and stores $\sim 25 \%$ of the ocean's anthropogenic $\mathrm{CO}_{2}(76)$, may experience phytoplankton changes due to retreat of the
Arctic sea ice and strengthening of ocean stratification. These changes are expected to lead, respectively, to northward movement of productive areas and suppression of the spring bloom, substantially altering $\mathrm{CO}_{2}$ exchanges between the ocean and the atmosphere at high latitudes (77), although the net effect is uncertain. Rising temperatures may also lead to changes in the composition of different plankton functional groups (78). Expected changes in the relative dominance of diatoms and calcareous plankton can strongly affect the biological cycling of carbon. Such a change was a possible contributor to $\mathrm{CO}_{2}$ differences between Pleistocene glacial and interglacial periods (79). Similarly, shifts from diatom- to flagellate-dominated systems in temperate latitudes and increased

\section{Climate change}

In areas inhabited by mosquitoes such as Aedes and Anopheles-important vectors for malaria, yellow fever, dengue, chikungunya, lymphatic filariasis, and Japanese encephalitis-temperatures are rising and rainfall patterns are shifting, and these changes are predicted to continue (111).

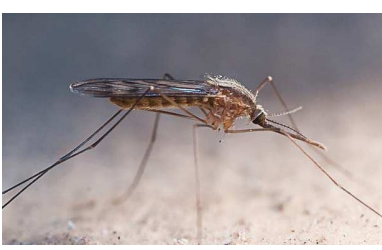

Image credit: Anders Lindström

\section{Species range shifts}

Abundance and distribution of mosquitoes is limited by temperature and rainfall. Expansion of Aedes has been linked to warming, affecting potential for disease transmission $(112,113)$. The altitudinal distribution of malaria has shifted with increased temperature (60), and the shift is projected to continue (114). Areas suitable for disease transmission are expanding or shifting, as areas previously unsuitable become suitable for the vector to survive $(60,114)$ while the transmis sion season is also getting longer (115).

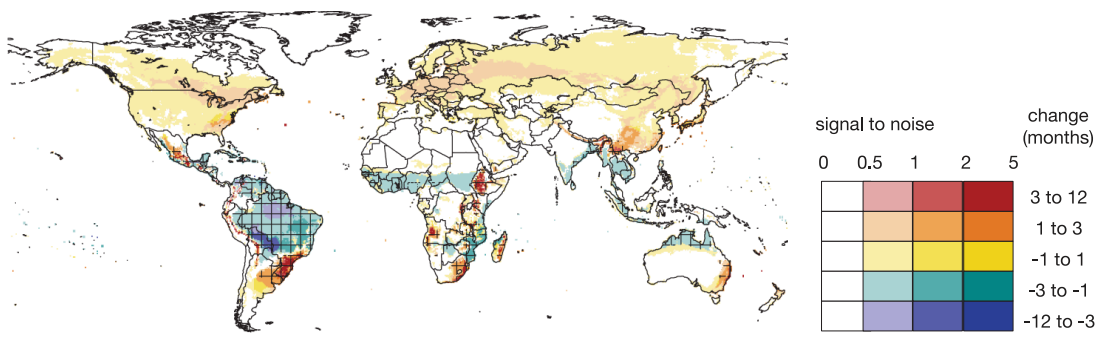

Projected changes in length of malaria transmission season between 1980-2010 and 2069-2099 (2080s) under the rcp85 emissions scenario. The different saturations reflect the change in months and associated signal-to-noise ratio ( $y$ and $x$ axis on the scale, respectively) (116).

\section{Governance challenges}

Early detection and possible eradication methods need to be put into place, while more accurate regional modeling should advise efficient resource allocation.

$$
\text { U }
$$

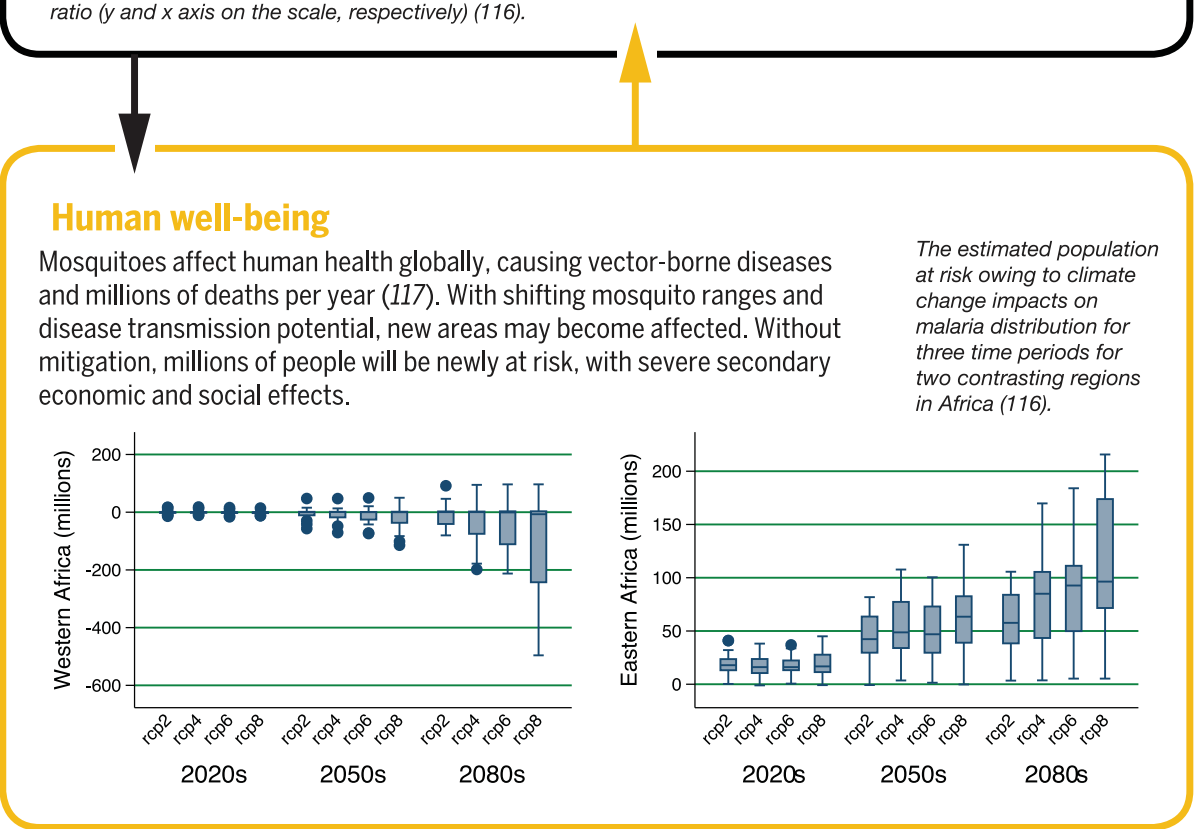

Fig. 3. Mosquito species on the move as vectors of disease. Climate change has facilitated an increase in the distribution of disease vectors, with considerable human cost and associated governance challenges. The bars in the human well-being graphs represent the minimum and maximum ranges; the boxes depict the 25th, 50th, and 75th percentiles of the distribution; and the circles represent outliers. See also (60, 111-117). 
microbial remineralization, both associated with warming, are expected to reduce the efficiency of the biological pump and therefore affect atmospheric $\mathrm{CO}_{2}(80)$.

Temperature-related changes in phytoplankton distributions will also affect production of dimethyl sulfide (DMS), which contributes sulfur particles to the atmosphere and seeds cloud formation (81). These particles are expected to decrease surface temperature, but they may also act as a greenhouse gas, so the net effect on climate warming is not yet clear. There is no simple relationship between DMS production and phytoplankton biomass, chlorophyll concentration, or primary production, which suggests a complex regulation of DMS production by the whole marine planktonic ecosystem and the physical environment controlling it. Hence, current climate models cannot give an estimate of the strength or even the direction of the phytoplankton-DMSclimate feedback.

Climate-influenced links between terrestrial and marine regions may also lead to species redistribution and climate feedbacks. For example, episodic land-atmosphere-ocean deposition of iron (e.g., pulses of Sahara dust) produces phytoplankton blooms (82) and enhances carbon export via the biological pump. Changes to the phytoplanktondriven drawdown of atmospheric $\mathrm{CO}_{2}$ may therefore arise through changes in the spatial distribution of iron deposition, which may be affected by changes in drought conditions, agricultural practices, and largescale atmospheric circulation (83). These complex processes-not only driven by climate-induced species redistribution but also affecting the climate system itself-need to be incorporated into climate models to improve future projections (65).

\section{Governance challenges}

The impacts of the global redistribution of species on human welfare and ecosystem services require new governance mechanisms for biodiversity conservation and management. A dynamic and multilevel legal and policy approach is needed to address the effects of species range limits moving across local, national, and international jurisdictional boundaries. The development of international guidance where laws do not yet exist will need to account for different legal regimes, resources, and national capacities.

Shifts in species distributions will require changes in the objectives of conservation law, which have traditionally emphasized in situ conservation and retention of historical conditions. Objectives should acknowledge that species will move beyond their traditional ranges, that novel ecosystems will inevitably be created and that historic ecosystems may disappear, as a consequence of such movements (84). The experience of transjurisdictional managed relocations (conservation introductions outside of historical ranges) may inform the development of risk assessment processes that must navigate the complex ethical challenges arising from novel interactions (85) and risks of collateral damage (86). Moreover, communication among relevant agencies throughout the new and former ranges of shifting species is essential to avoid in-

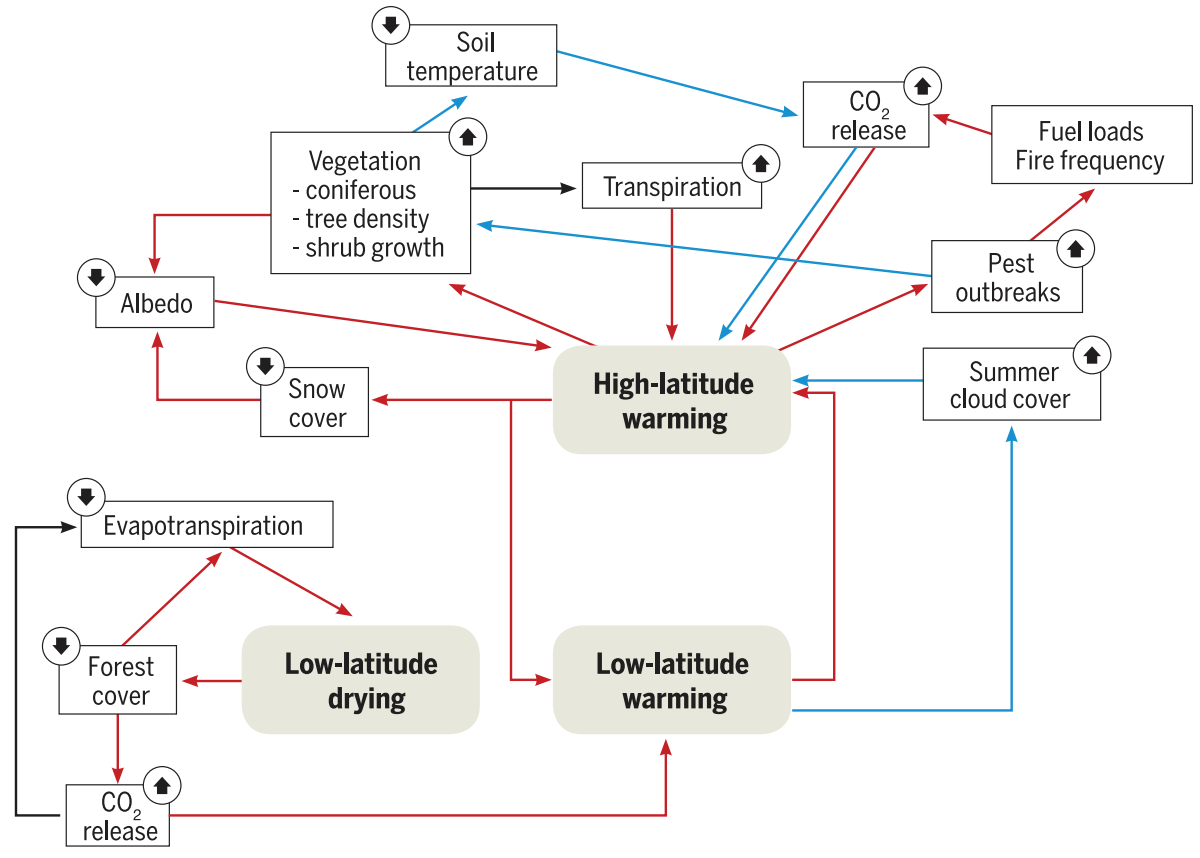

Fig. 4. Climate feedbacks and processes driven by the redistribution of plant species at high latitudes. Climate affects vegetation at high latitudes directly through climatic processes but also indirectly through pests like defoliators and bark beetles that are moving northward and upslope in boreal forests. Some processes increase warming (red arrows), whereas others may serve to decrease warming (blue arrows). Increasing shrub canopy cover in the Arctic at high latitudes may reduce soil temperatures locally through a buffering effect, potentially slowing down $\mathrm{CO}_{2}$ carbon release due to permafrost degradation, thus acting to slow climate warming. However, greening of the Arctic also decreases albedo, which accelerates warming.

vesting in protecting species in locations where they are no longer viable and yet failing to manage them appropriately in their new ranges.

Legal instruments are typically slow to change and often privilege the protection of property and development rights. Although this inertia provides certainty and stability, it underscores the need for flexible approaches that can respond quickly to novel threats arising from species movement or to capitalize on new opportunities. For example, the Landscape Resilience Program of Australia's Queensland government identified priority locations for new protected areas that would maximize available habitat for range-shifting species (87). Some jurisdictions with well-developed land use and development processes have moved toward adaptive development approvals, and Australia's fisheries management regime uses decision rules that automatically trigger new arrangements when predetermined environmental conditions are reached (88). Mechanisms of this sort could be used more widely to implement adaptive management for broader conservation purposes, such as management plans with preset increases in protective strategies that are triggered, or the automatic expansion of protection for habitat outside protected areas when certain climatic indicators are observed.

The changing distribution of species within countries, between countries, and between national borders and the global commons will require increased cooperation and governance across multiple scales among new stakeholders. The European Union's Habitats Directive [European Commission (EC), 1992] and Birds Directive (EC, 1979) are early examples of a cooperative approach to identifying and protecting networks of habitat across national borders. Initiatives such as the Transfrontier Conservation Areas in Southern Africa (Southern African Development Community Protocol, 1999) also provide useful insights to guide future multiscale and cross-border initiatives. Some challenges may also be addressed by increased use of dynamic management techniques. Several countries are already implementing dynamic ocean management practices for bycatch protection (89), though equivalent applications in a terrestrial context are more limited. Collaborative initiatives with indigenous communities may also offer new opportunities for conservation of range-shifting species. Indigenous communities can provide traditional ecological knowledge that complements remote sensing and field data and provides historical context (56), and new management arrangements may incentivize conservation activities.

\section{Earth systems and sustainable development}

Human survival, for urban and rural communities, depends on other life on Earth. The biological components of natural systems are "on the move," changing local abundances and geographical distributions of species. At the same time, the 
ability of people and communities to track these pervasive species redistributions and adapt to them is increasingly constrained by geopolitical boundaries, institutional rigidities, and inertias at all temporal and spatial scales.

In the coming century, all people and societies will face diverse challenges associated with development and sustainability, many of which will be exacerbated by the redistribution of species on the planet (Figs. 2 and 3). The impacts of species redistribution will intersect with at least 11 of the United Nations' Sustainable Development Goals (SDGs) (table S2) and will be particularly prominent for several of these SDGs.

SDG2 (Zero Hunger) requires feeding more than 9 billion people by 2050 (90). However, the ability to deliver food through agriculture will be altered via the direct effects of climate change, as the distributions and abundances of pollinators change and as plant pathogens and pests become more prevalent or emerge in new places as a result of global warming (91, 92). SDG3 (Good Health and Well-Being) is made more challenging by tropical illnesses spreading to new areas (58) and changes in food security and the distribution of economic wealth on local, regional, and global scales. Moreover, human well-being is also related to many other facets of society and culture, including attachment to place $(56,93)$ and the living environment found around us. The mental health of indigenous and rural communities, in particular, may be affected as species redistribution alters the capacity for traditional practices, subsistence, or local industries. The success of SDG13 (Climate Action) will depend on accounting for the direct and indirect influences of shifting organisms and associated feedbacks on our biosphere, yet these processes and feedbacks are rarely accounted for in projections of future climate. Sustainable management and the conservation of SDGs 14 and 15 (Life Below Water and Life on Land) are unlikely to be effective unless climate-driven alterations in species ranges and their profound ecosystem consequences are taken into consideration.

\section{Managing for movement}

Under extensive reshuffling of the world's biota, how should conservation goals and strategies for policy and implementation be developed to maximize long-term resilience of biodiversity and human systems? How should natural resource management across diverse, multiuse, multiscale land and seascapes be integrated to maximize resilience of both human and natural systems? How should specific threats and stressors (including their interactions) be managed while minimizing impacts on valued ecosystem assets? For the scientific community to help develop mitigation and adaptation strategies in the face of widespread change in species distribution and ecosystem functioning, a better understanding of the mechanisms underlying such changes is needed. Scientists also need access to real-time data streams, as well as to integrate this information into decisionsupport frameworks. Moreover, scientists and their institutions need to rapidly communicate advances and outcomes to the broader public and to policy-makers. However, the natural world responds in dynamic and unpredictable ways, and the phenomenon of species redistribution is not, nor will it ever be, fully understood or completely predictable. This uncertainty necessitates flexible and dynamic governance so adaptation to changing conditions can be rapid, maximizing opportunities and minimizing negative consequences.

\section{Underlying biological processes}

Because knowledge of the biological and ecological processes underlying resilience of organisms to predicted average and extreme environmental conditions is limited, the traits on which natural and anthropogenic selection will act are uncertain. For example, specific physiological mechanisms have been hypothesized to underlie the thermal ranges of ectothermic organisms (94), yet a lack of universality in the proposed mechanisms highlights a need for novel, multidisciplinary investigations (95). Large-scale, multigenerational experimental research programs are required to provide a robust understanding of the adaptive responses of organisms to environmental change and to determine the heritability of key traits, as recently has been achieved for sea turtles (96). Modeling approaches, lab and field-based experimental manipulations, and field-based monitoring programs need to be combined with more effective policy communication to understand and implement responses to species redistributions.

\section{Monitoring programs}

To best adjust to species redistributions, gaps in understanding need to be acknowledged and filled through hypothesis testing. Our understanding is weakest in poorly surveyed regions such as the tropics and Antarctica (8). As range shifts continue to unfold, there will be opportunities to refine our understanding of the process, but taking advantage of these opportunities requires access to consistent, high-quality, nearreal-time data on a series of environmental and biological parameters (97).

The current absence of a global, comprehensive, coordinated biodiversity monitoring system is a major obstacle to our understanding of climate change implications for natural systems. Thus far, extensive global cooperation and progress have been achieved in terms of coordinating the collection and distribution of physical and chemical environmental monitoring data. For example, the Global Climate Observing System facilitated international agreement and a global commitment toward consistent monitoring of climate variables, ultimately supporting the development of spatiotemporally-explicit and uncertaintyexplicit predictions about changes in our climate (98). Ongoing efforts through the Group on Earth Observation Biodiversity Observation Network and the Intergovernmental Oceanographic Commission Global Ocean Observing System are beginning to implement the use of Essential Biodiversity Variables (41) and ecosystem Essential Ocean Variables (99), respectively, but the process is slow and underresourced. A global, robust biodiversity monitoring system that successfully integrates field and remote-sensing data could substantially improve our ability to manage the changes to come while potentially driving faster mitigation measures (100).

\section{Incorporating species on the move into integrated assessment models}

Knowledge of underlying biological processes and access to real-time data are necessary but not sufficient for informed responses. Improved capacity to model linkages and feedbacks between species range shifts and ecosystem functioning, food security, human health, and the climate is required. Modeling is essential to reliably project the potential impacts of alternative scenarios and policy options on human well-being, as the basis for evidence-based policy and decision support (101). One avenue forward is to incorporate species redistribution and its associated effects into integrated assessment models (IAMs) (102), which are used widely within the climate science community and are now being rapidly mobilized and extended to address synergies and trade-offs between multiple SDGs (103). IAMs offer a promising approach for connecting processes, existing data, and scenarios of demographic, social, and economic change and governance. Although species distribution models are commonplace, advances are needed to connect species redistribution with ecosystem integrity (104) and feedbacks between humans and the biosphere.

\section{Communication for public and policy}

How does the scientific community engage effectively with the public on the issue of species redistribution and its far-reaching impacts? Part of the answer could be citizen science and participatory observing approaches, in which community members are directly involved in data collection and interpretation (105). These tools can help to address gaps in both data and communication (100). When properly designed and carefully tailored to local issues, such approaches can provide quality data, cost-effectively and sustainably, while simultaneously building capacity among local constituents and prompting practical and effective management interventions (106).

\section{Conclusions}

The breadth and complexity of the issues associated with the global redistribution of species driven by changing climate are creating profound challenges, with species movements already affecting societies and regional economies from the tropics to polar regions. Despite mounting evidence for these impacts, current global goals, policies, and international agreements do not sufficiently consider species range shifts in their formulation or targets. Enhanced awareness, supported by appropriate governance, will provide the best chance of minimizing negative consequences while maximizing opportunities arising from species movements-movements that, with or without effective emission reduction, will continue for the foreseeable future, owing to the inertia in the climate system. 


\section{REFERENCES AND NOTES}

1. M. B. Davis, R. G. Shaw, Range shifts and adaptive responses to Quaternary climate change. Science 292, 673-679 (2001). doi: 10.1126/science.292.5517.673; pmid: 11326089

2. B. R. Rosen, "Reef coral biogeography and climate through the late Cainozoic: Just islands in the sun or a critical pattern of islands" in Fossils and Climate, P. J. Brenchley, Ed. (Geol. J. Special Issue 11. Wiley, Chichester, 1984), pp. 201-262.

3. N. S. Diffenbaugh, C. B. Field, Changes in ecologically critical terrestrial climate conditions. Science 341, 486-492 (2013). doi: 10.1126/science.1237123; pmid: 23908225

4. D. B. Kemp, K. Eichenseer, W. Kiessling, Maximum rates of climate change are systematically underestimated in the geological record. Nat. Commun. 6, 8890 (2015) doi: 10.1038/ncomms9890; pmid: 26555085

5. I.-C. Chen, J. K. Hill, R. Ohlemüller, D. B. Roy, C. D. Thomas, Rapid range shifts of species associated with high levels of climate warming. Science 333, 1024-1026 (2011) doi: 10.1126/science.1206432; pmid: 21852500

6. E. S. Poloczanska et al., Global imprint of climate change on marine life. Nat. Clim. Chang. 3, 919-925 (2013). doi: 10.1038/nclimate1958

7. Conservation of Arctic Flora and Fauna (CAFF), "Arctic biodiversity assessment: Report for policy makers" (CAFF, 2013); www.arcticbiodiversity.is/the-report/report-for-policymakers.

8. J. Lenoir, J. C. Svenning, Climate-related range shifts - a global multidimensional synthesis and new research directions. Ecography 38, 15-28 (2015). doi: 10.1111/ecog.00967

9. A. M. Lawing, P. D. Polly, Pleistocene climate, phylogeny, and climate envelope models: An integrative approach to better understand species' response to climate change. PLOS ONE 6, e28554 (2011). doi: 10.1371/journal.pone.0028554 pmid: 22164305

10. Intergovernmental Panel on Climate Change (IPCC), "Climate Change 2014: Synthesis Report. Contribution of Working Groups I, II and III to the Fifth Assessment Report of the Intergovernmental Panel on Climate Change" (IPCC, 2014); www.ipcc.ch/report/ar5/syr/.

11. United Nations Framework Convention on Climate Change Conference of Parties (COP), "Paris Agreement FCCC/CP/ 2015/L.9/Rev.1" (2015); http://unfccc.int/resource/docs/ 2015/cop21/eng/I09r01.pdf.

12. S. E. Williams, L. P. Shoo, J. L. Isaac, A. A. Hoffmann, G. Langham, Towards an integrated framework for assessing the vulnerability of species to climate change. PLOS Biol. 6 , 2621-2626 (2008). doi: 10.1371/journal.pbio.0060325; pmid: 19108608

13. A. E. Bates et al., Defining and observing stages of climatemediated range shifts in marine systems. Glob. Environ. Change 26, 27-38 (2014). doi: 10.1016/ j.gloenvcha.2014.03.009

14. A. T. Peterson et al., Ecological Niches And Geographic Distributions (MPB-49). Monographs in Population Biology (Princeton Univ. Press, 2011)

15. M. P. Berg et al., Adapt or disperse: Understanding species persistence in a changing world. Glob. Change Biol. 16 587-598 (2010). doi: 10.1111/j.1365-2486.2009.02014.x

16. C. J. B. Sorte, S. L. Williams, J. T. Carlton, Marine range shifts and species introductions: Comparative spread rates and community impacts. Glob. Ecol. Biogeogr. 19, 303-316 (2010). doi: 10.1111/j.1466-8238.2009.00519.x

17. I.-C. Chen et al., Elevation increases in moth assemblages over 42 years on a tropical mountain. Proc. Natl. Acad. Sci. U.S.A. 106, 1479-1483 (2009). doi: 10.1073/pnas.0809320106; pmid: 19164573

18. N. K. Dulvy et al., Climate change and deepening of the North Sea fish assemblage: A biotic indicator of warming seas. J. Appl. Ecol. 45, 1029-1039 (2008). doi: 10.1111/j.1365-2664.2008.01488.x

19. B. R. Scheffers, T. A. Evans, S. E. Williams, D. P. Edwards, Microhabitats in the tropics buffer temperature in a globally coherent manner. Biol. Lett. 10, 20140819 (2014). doi: 10.1098/rsbl.2014.0819; pmid: 25540160

20. J. Lenoir et al., Going against the flow: Potential mechanisms for unexpected downslope range shifts in a warming climate. Ecography 33, 295-303 (2010). doi: 10.1111/j.1600-0587.2010.06279.x

21. F. Valladares et al., The effects of phenotypic plasticity and local adaptation on forecasts of species range shifts under climate change. Ecol. Lett. 17, 1351-1364 (2014). doi: 10.1111/ele.12348; pmid: 25205436
22. M. B. Araújo et al., Heat freezes niche evolution. Ecol. Lett. 16 1206-1219 (2013). doi: 10.1111/ele.12155; pmid: 23869696

23. S. E Gilman, M. C. Urban, J. Tewksbury, G. W. Gilchrist, R. D. Holt, A framework for community interactions under climate change. Trends Ecol. Evol. 25, 325-331 (2010). doi: 10.1016/j.tree.2010.03.002: pmid: 20392517

24. A. Vergés et al., The tropicalization of temperate marine ecosystems: Climate-mediated changes in herbivory and community phase shifts. Proc. R. Soc. London Ser. B 281, 20140846 (2014). doi: 10.1098/rspb.2014.0846; pmid: 25009065

25. A. E. Cahill et al., How does climate change cause extinction? Proc. R. Soc. London Ser. B 280, 20121890 (2013). pmid: 23075836

26. R. B. Aronson et al., No barrier to emergence of bathyal king crabs on the Antarctic shelf. Proc. Natl. Acad. Sci. U.S.A. 112, 12997-13002 (2015). doi: 10.1073/pnas.1513962112; pmid: 26417090

27. O. E. Sala et al., Global biodiversity scenarios for the year 2100. Science 287, 1770-1774 (2000). doi: 10.1126/ science.287.5459.1770; pmid: 10710299

28. P. L. Zarnetske, D. K. Skelly, M. C. Urban, Biotic multipliers of climate change. Science 336, 1516-1518 (2012) doi: 10.1126/science.1222732; pmid: 22723403

29. K. C. Cavanaugh et al., Poleward expansion of mangroves is a threshold response to decreased frequency of extreme cold events. Proc. Natl. Acad. Sci. U.S.A. 111, 723-727 (2014) doi: 10.1073/pnas.1315800111; pmid: 24379379

30. A. Vergés et al., Long-term empirical evidence of ocean warming leading to tropicalization of fish communities, increased herbivory, and loss of kelp. Proc. Natl. Acad. Sci. U.S.A. 113, 13791-13796 (2016) doi: 10.1073/pnas.1610725113; pmid: 27849585

31. T. Wernberg et al., Climate-driven regime shift of a temperate marine ecosystem. Science 353, 169-172 (2016). doi: 10.1126/science.aad8745; pmid: 27387951

32. A. S. Weed, M. P. Ayres, J. A. Hicke, Consequences of climate change for biotic disturbances in North American forests. Ecol. Monogr. 83, 441-470 (2013). doi: 10.1890/13-0160.1

33. M. Fossheim et al., Recent warming leads to a rapid borealization of fish communities in the Arctic. Nat. Clim. Chang. 5, 673-677 (2015). doi: 10.1038/nclimate2647

34. H. W. Paerl, V. J. Paul, Climate change: Links to globa expansion of harmful cyanobacteria. Water Res. 46 1349-1363 (2012). doi: 10.1016/j.watres.2011.08.002; pmid: 21893330

35. L. M. Ochoa-Ochoa, P. Rodríguez, F. Mora, O. Flores-Villela, R. J. Whittaker, Climate change and amphibian diversity patterns in Mexico. Biol. Conserv. 150, 94-102 (2012). doi: 10.1016/i.biocon.2012.03.010

36. L. Buisson, G. Grenouillet, S. Villéger, J. Canal, P. Laffaille, Toward a loss of functional diversity in stream fish assemblages under climate change. Global Change Biol. 19 387-400 (2013). doi: 10.1111/gcb.12056; pmid: 23504778

37. T. H. Oliver et al., Biodiversity and resilience of ecosystem functions. Trends Ecol. Evol. 30, 673-684 (2015). doi: 10.1016/j.tree.2015.08.009; pmid: 26437633

38. J. R. Malcolm, C. Liu, R. P. Neilson, L. Hansen, L. Hannah, Global warming and extinctions of endemic species from biodiversity hotspots. Conserv. Biol. 20, 538-548 (2006). doi: 10.1111/j.1523-1739.2006.00364.x; pmid: 16903114

39. I. M. D. Maclean, R. J. Wilson, Recent ecological responses to climate change support predictions of high extinction risk. Proc. Natl. Acad. Sci. U.S.A. 108, 12337-12342 (2011) doi: 10.1073/pnas.1017352108; pmid: 21746924

40. M. C. Urban, Accelerating extinction risk from climate change. Science $348,571-573$ (2015) doi: 10.1126/science.aaa4984; pmid: 25931559

41. H. M. Pereira et al., Essential biodiversity variables. Science 339, 277-278 (2013). doi: 10.1126/science.1229931; pmid: 23329036

42. S. Dullinger et al., Extinction debt of high-mountain plants under twenty-first-century climate change. Nat. Clim Chang. 2, 619-622 (2012). doi: 10.1038/nclimate1514

43. J. A. E. Stewart et al., Revisiting the past to foretell the future: Summer temperature and habitat area predict pika extirpations in California. J. Biogeogr. 42, 880-890 (2015). doi: 10.1111/jbi.12466

44. I. Gynther, N. Waller, L. K.-P. Leung, "Confirmation of the extinction of the Bramble Cay melomys Melomys rubicola on Bramble Cay, Torres Strait: Results and conclusions from a comprehensive survey in August-September 2014" (Report to the Department of Environment and Heritage
Protection, Queensland Government, Brisbane, 2016): www.ehp.qld.gov.au/wildlife/threatened-species/documents/ bramble-cay-melomys-survey-report.pdf.

45. S. Finnegan et al., Paleontological baselines for evaluating extinction risk in the modern oceans. Science 348 567-570 (2015). doi: 10.1126/science.aaa6635: pmid: 25931558

46. C. J. Brown et al., Ecological and methodological drivers of species' distribution and phenology responses to climate change. Global Change Biol. 22, 1548-1560 (2016). doi: 10.1111/gcb.13184; pmid: 26661135

47. J. S. Compton, Pleistocene sea-level fluctuations and human evolution on the southern coastal plain of South Africa. Quat. Sci. Rev. 30, 506-527 (2011). doi: 10.1016/ i.quascirev.2010.12.012

48. J. D. Bell et al., Mixed responses of tropical Pacific fisheries and aquaculture to climate change. Nat. Clim. Chang. 3, 591-599 (2013). doi: 10.1038/nclimate1838

49. M. Hanewinkel, D. A. Cullmann, M.-J. Schelhaas, G.-J. Nabuurs, N. E. Zimmermann, Climate change may cause severe loss in the economic value of European forest land. Nat. Clim. Chang. 3, 203-207 (2013). doi: $10.1038 /$ nclimate1687

50. E. Civantos, W. Thuiller, L. Maiorano, A. Guisan, M. B. Araújo, Potential impacts of climate change on ecosystem services in Europe: The case of pest control by vertebrates. Bioscience 62, 658-666 (2012). doi: 10.1525/bio.2012.62.7.8

51. B. M. Campbell et al., Reducing risks to food security from climate change. Glob. Food Secur. 11, 34-43 (2016) doi: 10.1016/j.gfs.2016.06.002

52. M. Baca, P. Läderach, J. Haggar, G. Schroth, O. Ovalle, An integrated framework for assessing vulnerability to climate change and developing adaptation strategies for coffee growing families in Mesoamerica. PLOS ONE 9 , e88463 (2014). doi: 10.1371/journal.pone.0088463; pmid: 24586328

53. D. C. Gledhill et al., Collaborative approaches to accessing and utilising historical citizen science data: A case-study with spearfishers from eastern Australia. Mar. Freshw. Res. 66 195-201 (2014). doi: 10.1071/MF14071

54. J. Ruiz, L. Prieto, D. Astorga, A model for temperature control of jellyfish (Cotylorhiza tuberculata) outbreaks: A causa analysis in a Mediterranean coastal lagoon. Ecol. Modell. 233, 59-69 (2012). doi: 10.1016/j.ecolmodel.2012.03.019

55. S. D. Ling, C. R. Johnson, S. D. Frusher, K. R. Ridgway, Overfishing reduces resilience of kelp beds to climate-driven catastrophic phase shift. Proc. Natl. Acad. Sci. U.S.A. 106, 22341-22345 (2009). doi: 10.1073/pnas.0907529106; pmid: 20018706

56. T. Mustonen, Communal visual histories to detect environmental change in northern areas: Examples of emerging North American and Eurasian practices. Ambio 44 766-777 (2015). doi: 10.1007/s13280-015-0671-7: pmid: 26008615

57. K. E. Jones et al., Global trends in emerging infectious diseases. Nature 451, 990-993 (2008). doi: 10.1038/nature06536; pmid: 18288193

58. X. Wu, Y. Lu, S. Zhou, L. Chen, B. Xu, Impact of climate change on human infectious diseases: Empirical evidence and human adaptation. Environ. Int. 86, 14-23 (2016). doi: 10.1016/j.envint.2015.09.007; pmid: 26479830

59. World Health Organization (WHO), "Malaria fact sheet" (WHO, 2016); www.who.int/mediacentre/factsheets/ fs094/en/.

60. A. S. Siraj et al., Altitudinal changes in malaria incidence in highlands of Ethiopia and Colombia. Science 343, 1154-1158 (2014). doi: 10.1126/science.1244325; pmid: 24604201

61. L. V. Weatherdon, A. K. Magnan, A. D. Rogers, U. R. Sumaila, W. W. L. Cheung, Observed and projected impacts of climate change on marine fisheries, aquaculture, coastal tourism, and human health: An update. Front. Mater. Sci. 3, 48 (2016). doi: 10.3389/fmars.2016.00048

62. J. J. Wiens, Climate-related local extinctions are already widespread among plant and animal species. PLOS Biol. 14 e2001104 (2016). doi: 10.1371/journal.pbio.2001104; pmid: 27930674

63. O. S. Astthorsson, H. Valdimarsson, A. Gudmundsdottir, G. J. Óskarsson, Climate-related variations in the occurrence and distribution of mackerel (Scomber scombrus) in Icelandic waters. ICES J. Mar. Sci. 69, 1289-1297 (2012). doi: 10.1093/icesjms/fss084

64. M. Brambilla, P. Pedrini, A. Rolando, D. E. Chamberlain, Climate change will increase the potential conflict between 
skiing and high-elevation bird species in the Alps. J. Biogeogr 43, 2299-2309 (2016). doi: 10.1111/jbi.12796

65. I. C. Prentice, S. Williams, P. Friedlingstein, "Biosphere feedbacks and climate change" (Grantham Institute Briefing paper no. 12, Imperial College London, 2015)

66. W. V. Reid et al., Environment and development. Earth system science for global sustainability: Grand challenges. Science 330, 916-917 (2010). doi: 10.1126/science.1196263; pmid: 21071651

67. F. S. Chapin 3rd et al., Role of land-surface changes in arctic summer warming. Science 310, 657-660 (2005). doi: 10.1126/science.1117368; pmid: 16179434

68. R. G. Pearson et al., Shifts in Arctic vegetation and associated feedbacks under climate change. Nat. Clim. Chang. 3 673-677 (2013). doi: 10.1038/nclimate1858

69. A. L. Swann, I. Y. Fung, S. Levis, G. B. Bonan, S. C. Doney, Changes in Arctic vegetation amplify high-latitude warming through the greenhouse effect. Proc. Natl. Acad. Sci. U.S.A. 107, 1295-1300 (2010). doi: 10.1073/pnas.0913846107; pmid: 20080628

70. M. P. Cox et al., Amazonian forest dieback under climatecarbon cycle projections for the 21st century. Theor. Appl. Climatol. 78, 137-156 (2004). doi: 10.1007/s00704-004-0049-4

71. R. A. Garcia, M. Cabeza, C. Rahbek, M. B. Araúijo, Multiple dimensions of climate change and their implications for biodiversity. Science 344, 1247579 (2014). doi: 10.1126/science.1247579; pmid: 24786084

72. T. J. Cudmore, N. Björklund, A. L. Carroll, B. Staffan Lindgren, Climate change and range expansion of an aggressive bark beetle: Evidence of higher beetle reproduction in naïve host tree populations. J. Appl. Ecol. 47, 1036-1043 (2010). doi: 10.1111/j.1365-2664.2010.01848.x

73. E. S. Kasischke, M. R. Turetsky, Recent changes in the fire regime across the North American boreal region-Spatial and temporal patterns of burning across Canada and Alaska. Geophys. Res. Lett. 33, L09703 (2006). doi: 10.1029/2006GL025677

74. J. Chen et al.. Microclimate in forest ecosystem and landscape ecology: Variations in local climate can be used to monitor and compare the effects of different management regimes. Bioscience 49, 288-297 (1999). doi: $10.2307 / 1313612$

75. D. Blok et al., The response of Arctic vegetation to the summer climate: Relation between shrub cover, NDVI, surface albedo and temperature. Environ. Res. Lett. 6. 035502 (2011). doi: 10.1088/1748-9326/6/3/035502

76. C. L. Sabine et al., The oceanic sink for anthropogenic $\mathrm{CO}_{2}$. Science 305, 367-371 (2004). doi: 10.1126/science.1097403; pmid: 15256665

77. A. Yool, E. E. Popova, A. C. Coward, Future change in ocean productivity: Is the Arctic the new Atlantic? J. Geophys. Res. 120, 7771-7790 (2015). doi: 10.1002/2015JC011167

78. J. J. Polovina, P. A. Woodworth, Declines in phytoplankton cell size in the subtropical oceans estimated from satellite remotely-sensed temperature and chlorophyll, 1998-2007. Deep Sea Res. Part I/ 77-80, 82-88 (2012) doi: 10.1016/j.dsr2.2012.04.006

79. K. E. Kohfeld, C. Le Quéré, S. P. Harrison, R. F. Anderson, Role of marine biology in glacial-interglacial $\mathrm{CO}_{2}$ cycles. Science 308, 74-78 (2005). doi: 10.1126/science.1105375 pmid: 15802597

80. P. C. Reid et al., Chapter 1. Impacts of the oceans on climate change. Adv. Mar. Biol. 56, 1-150 (2009) doi: 10.1016/S0065-2881(09)56001-4; pmid: 19895974

81. O. W. Wingenter et al., Unexpected consequences of increasing $\mathrm{CO}_{2}$ and ocean acidity on marine production of DMS and $\mathrm{CH}_{2} \mathrm{Cll}$ : Potential climate impacts. Geophys. Res. Lett. 34, L05710 (2007). doi: 10.1029/2006GL028139

82. J. H. Martin, Glacial-interglacial $\mathrm{CO}_{2}$ change: The iron hypothesis. Paleoceanography 5, 1-13 (1990) doi: 10.1029/PA005i001p00001

83. S. A. Robinson, D. J. Erickson III, Not just about sunburnThe ozone hole's profound effect on climate has significant implications for Southern Hemisphere ecosystems. Global Change Biol. 21, 515-527 (2015). doi: 10.1111/gcb.12739; pmid: 25402975

84. P. McCormack, J. McDonald, Adaptation strategies for biodiversity conservation: Has Australian law got what it takes? Environ. Plann. Law J. 31, 114-136 (2014).
85. A. A. Burbidge et al., Is Australia ready for assisted colonization? Policy changes required to facilitate translocations under climate change. Pac. Conserv. Biol. 17 259-269 (2011). doi: 10.1071/PC110259

86. A. Ricciardi, D. Simberloff, Assisted colonization: Good intentions and dubious risk assessment. Trends Ecol. Evol. 24, 476-477 (2009). doi: 10.1016/j.tree.2009.05.005

87. A. Reside et al., "Climate change refugia for terrestrial biodiversity: Defining areas that promote species persistence and ecosystem resilience in the face of global climate change" (National Climate Change Adaptation Research Facility, 2013).

88. J. McDonald, M. C. Styles, Legal strategies for adaptive management under climate change. J. Environ. Law 26, 25-53 (2014). doi: 10.1093/jel/equ003

89. A. J. Hobday et al., Dynamic ocean management: Integrating scientific and technological capacity with law, policy and management. Stanford Environ. Law J. 33, 125-165 (2014).

90. H. C. J. Godfray et al., Food security: The challenge of feeding 9 billion people. Science 327, 812-818 (2010). doi: 10.1126/science.1185383; pmid: 20110467

91. S. J. Hegland, A. Nielsen, A. Lázaro, A.-L. Bjerknes, Ø. Totland, How does climate warming affect plant-pollinator interactions? Ecol. Lett. 12, 184-195 (2009). doi: 10.1111/j.1461-0248.2008.01269.x; pmid: 19049509

92. D. P. Bebber, M. A. T. Ramotowski, S. J. Gurr, Crop pests and pathogens move polewards in a warming world. Nat. Clim. Chang. 3, 985-988 (2013). doi: 10.1038/nclimate1990

93. W. N. Adger, J. Barnett, K. Brown, N. Marshall, K. O'Brien, Cultural dimensions of climate change impacts and adaptation. Nat. Clim. Chang. 3, 112-117 (2013). doi: 10.1038 /nclimate1666

94. H. O. Pörtner et al., "Ocean systems" in Climate Change 2014 Impacts, Adaptation, and Vulnerability. Part A: Global and Sectoral Aspects. Contribution of Working Group II to the Fifth Assessment Report of the Intergovernmental Panel on Climate Change (Cambridge Univ. Press, 2014).

95. T. D. Clark, E. Sandblom, F. Jutfelt, Aerobic scope measurements of fishes in an era of climate change: Respirometry, relevance and recommendations. J. Exp. Biol. 216. 2771-2782 (2013). doi: 10.1242/jeb.084251; pmid: 23842625

96. J. N. Tedeschi et al., Heritable variation in heat shock gene expression: A potential mechanism for adaptation to therm stress in embryos of sea turtles. Proc. R. Soc. London Ser. B 283, 20152320 (2016). doi: 10.1098/rspb.2015.2320; pmid: 26763709

97. N. Pettorelli et al., Satellite remote sensing for applied ecologists: Opportunities and challenges. J. Appl. Ecol. 51 839-848 (2014). doi: 10.1111/1365-2664.12261

98. S. Bojinski et al., The Concept of essential climate variables in support of climate research, applications, and policy. Bull. Am. Meteorol. Soc. 95, 1431-1443 (2014). doi: 10.1175/BAMS-D-13-00047.1

99. A. J. Constable et al., Developing priority variables ("ecosystem Essential Ocean Variables" - eEOVs) for observing dynamics and change in Southern Ocean ecosystems. J. Mar. Syst. 161, 26-41 (2016) doi: 10.1016/j.jmarsys.2016.05.003

100. N. Pettorelli et al., Framing the concept of satellite remote sensing essential biodiversity variables: Challenges and future directions. Remote Sens. Ecol. Conserv. 2, 122-131 (2016). doi: 10.1002/rse2.15

101. IPBES, "Summary for policymakers of the methodological assessment of scenarios and models of biodiversity and ecosystem services of the Intergovernmental SciencePolicy Platform on Biodiversity and Ecosystem Services" (Secretariat of the Intergovernmental Science-Policy Platform on Biodiversity and Ecosystem Services, 2016); www.ipbes.net/resources/publications/13.

102. M. Harfoot et al., Integrated assessment models for ecologists: The present and the future. Global. Ecol. Biogeogr. 23. 124-143 (2014). doi: 10.1111/geb.12100

103. D. P. van Vuuren et al., Pathways to achieve a set of ambitious global sustainability objectives by 2050 : Explorations using the IMAGE integrated assessment model. Technol. Forecast. Soc. Change 98, 303-323 (2015). doi: 10.1016/j.techfore.2015.03.005
104. P. Lehodey, I. Senina, R. Murtugudde, A spatial ecosystem and populations dynamics model (SEAPODYM) Modeling of tuna and tuna-like populations. Prog. Oceanogr. 78, 304-318 (2008). doi: 10.1016/j.pocean.2008.06.004

105. R. Bonney et al., Next steps for citizen science. Science 343 , 1436-1437 (2014). doi: 10.1126/science.1251554 pmid: 24675940

106. F. Danielsen et al., A multicountry assessment of tropical resource monitoring by local communities. Bioscience 64 236-251 (2014). doi: 10.1093/biosci/biu001

107. B. Forbes, "Arctic vegetation cover: Patterns, processes and expected change" in The New Arctic, B. Evengård, J. N. Larsen, P. Öyvind, Eds. (Springer, 2015).

108. G. B. Hill, G. H. R. Henry, Responses of High Arctic wet sedge tundra to climate warming since 1980 . Glob. Change Biol. 17, 276-287 (2011). doi: 10.1111/ j.1365-2486.2010.02244.x

109. D. Verbyla, The greening and browning of Alaska based on 1982-2003 satellite data. Global Ecol. Biogeogr. 17. 547-555 (2008). doi: 10.1111/j.1466-8238.2008.00396.

110. E. Post et al., Ecological dynamics across the Arctic associated with recent climate change. Science 325 , 1355-1358 (2009). doi: 10.1126/science.1173113; pmid: 19745143

111. IPCC, "Climate Change 2014: Impacts, Adaptation, and Vulnerability. Part A: Global and Sectoral Aspects. Contribution of Working Group II to the Fifth Assessment Report of the Intergovernmental Panel on Climate Change" (Cambridge Univ. Press, 2014)

112. P. Martens et al., Climate change and future populations at risk of malaria. Global Environ. Change 9, S89-S107 (1999). doi: 10.1016/S0959-3780(99)00020-5

113. K. D. Lafferty, The ecology of climate change and infectious diseases. Ecology 90, 888-900 (2009). doi: 10.1890/08-0079.1; pmid: 19449681

114. S. J. Ryan et al., Mapping physiological suitability limits for malaria in Africa under climate change. Vector Borne Zoonotic Dis. 15, 718-725 (2015) doi: 10.1089/vbz.2015.1822; pmid: 2657995

115. S. I. Hay et al., Climate change and the resurgence of malaria in the East African highlands. Nature 415, 905-909 (2002). doi: 10.1038/415905a; pmid: 11859368

116. C. Caminade et al., Impact of climate change on global malaria distribution. Proc. Natl. Acad. Sci. U.S.A. 111, 3286-3291 (2014). doi: 10.1073/pnas.1302089111; pmid: 24596427

117. WHO, "World health report: Executive summary" (WHO, 1996); www.who.int/whr/1996/media centre/ executive_summary1/en/index9.html.

\section{ACKNOWLEDGMENTS}

We thank the attendees of the international Species on the Move conference held in Hobart, Tasmania, Australia, in February 2016 G.T.P., E.W., and T.W. were supported by ARC Future Fellowships (FT140100596, FT110100597, and FT110100174, respectively). R.A.G.'s participation was made possible by the South African National Research Foundation (KIC 98457 and Blue Skies 449888). M.A.J. was funded by Yale Climate and Energy Institute. T.M.'s participation was supported by the WAPEAT (Finnish Academy 263465) Project. J.M.P. was funded by the ARC Centre of Excellence for Coral Reef Studies and ARC DP130100250, J.M.St. was supported by ARC DP150101491, and S.A.R. was funded by ARC DP110101714. B.E. was supported by Nordforsk. A. Cooper [Institute for Marine and Antarctic Studies (IMAS)] assisted with the figures. The workshop and conference leading to this paper were supported by the University of Tasmania, IMAS, NOAA Fisheries Service, CSIRO, National Climate Change Adaptation Research Facility Natural Ecosystems Network, the lan Potter Foundation, the Antarctic Climate and Ecosystems Cooperative Research Centre, and the ARC Centre of Excellence for Environmental Decisions.

\section{SUPPLEMENTARY MATERIALS}

www.sciencemag.org/content/355/6332/eaai9214/suppl/DC1

Tables S1 and S2

References (118-135)

10.1126/science.aai9214 


\section{Science MIAAAS}

Biodiversity redistribution under climate change: Impacts on ecosystems and human well-being

Gretta T. Pecl, Miguel B. Araújo, Johann D. Bell, Julia Blanchard, Timothy C. Bonebrake, I-Ching Chen, Timothy D. Clark, Robert K. Colwell, Finn Danielsen, Birgitta Evengård, Lorena Falconi, Simon Ferrier, Stewart Frusher, Raquel A. Garcia, Roger B. Griffis, Alistair J. Hobday, Charlene Janion-Scheepers, Marta A. Jarzyna, Sarah Jennings, Jonathan Lenoir, Hlif I. Linnetved, Victoria Y. Martin, Phillipa C. McCormack, Jan McDonald, Nicola J. Mitchell, Tero Mustonen, John M. Pandolfi, Nathalie Pettorelli, Ekaterina Popova, Sharon A. Robinson, Brett R. Scheffers, Justine D. Shaw, Cascade J. B. Sorte, Jan M. Strugnell, Jennifer M. Sunday,

Mao-Ning Tuanmu, Adriana Vergés, Cecilia Villanueva, Thomas Wernberg, Erik Wapstra and Stephen E. Williams (March 30, 2017)

Science 355 (6332), . [doi: 10.1126/science.aai9214]

Editor's Summary

\section{Consequences of shifting species distributions}

Climate change is causing geographical redistribution of plant and animal species globally. These distributional shifts are leading to new ecosystems and ecological communities, changes that will affect human society. Pecl et al. review these current and future impacts and assess their implications for sustainable development goals.

Science, this issue p. eaai9214

This copy is for your personal, non-commercial use only.

Article Tools Visit the online version of this article to access the personalization and article tools:

http://science.sciencemag.org/content/355/6332/eaai9214

Permissions Obtain information about reproducing this article:

http://www.sciencemag.org/about/permissions.dtl

Science (print ISSN 0036-8075; online ISSN 1095-9203) is published weekly, except the last week in December, by the American Association for the Advancement of Science, 1200 New York Avenue NW, Washington, DC 20005. Copyright 2016 by the American Association for the Advancement of Science; all rights reserved. The title Science is a registered trademark of AAAS. 